Synergistic Effects of Turbine Wakes and Atmospheric Stability on Power Production at an Onshore Wind Farm

S. Wharton, J. K. Lundquist, N. Marjanovic

January 27, 2012 
This document was prepared as an account of work sponsored by an agency of the United States government. Neither the United States government nor Lawrence Livermore National Security, LLC, nor any of their employees makes any warranty, expressed or implied, or assumes any legal liability or responsibility for the accuracy, completeness, or usefulness of any information, apparatus, product, or process disclosed, or represents that its use would not infringe privately owned rights. Reference herein to any specific commercial product, process, or service by trade name, trademark, manufacturer, or otherwise does not necessarily constitute or imply its endorsement, recommendation, or favoring by the United States government or Lawrence Livermore National Security, LLC. The views and opinions of authors expressed herein do not necessarily state or reflect those of the United States government or Lawrence Livermore National Security, LLC, and shall not be used for advertising or product endorsement purposes.

This work performed under the auspices of the U.S. Department of Energy by Lawrence Livermore National Laboratory under Contract DE-AC52-07NA27344. 
Synergistic Effects of Turbine Wakes and Atmospheric Stability on Power Production at an Onshore Wind Farm

\author{
Sonia Wharton, Lawrence Livermore National Laboratory
}

With contributions from Julie K. Lundquist, University of Colorado, Boulder; National Renewable Energy Laboratory and Nikola Marjanovic, University of California, Berkeley; Lawrence Livermore National Laboratory

Technical Report LLNL-TR-524756

Prepared for the DOE Wind and Water Power Program

January 31,2012 
This document was prepared as an account of work sponsored by an agency of the United States government. Neither the United States government nor Lawrence Livermore National Security, LLC, nor any of their employees makes any warranty, expressed or implied, or assumes any legal liability or responsibility for the accuracy, completeness, or usefulness of any information, apparatus, product, or process disclosed, or represents that its use would not infringe privately owned rights. Reference herein to any specific commercial product, process, or service by trade name, trademark, manufacturer, or otherwise does not necessarily constitute or imply its endorsement, recommendation, or favoring by the United States government or Lawrence Livermore National Security, LLC. The views and opinions of authors expressed herein do not necessarily state or reflect those of the United States government or Lawrence Livermore National Security, LLC, and shall not be used for advertising or product endorsement purposes.

This work performed under the auspices of the U.S. Department of Energy by Lawrence Livermore National Laboratory under Contract DE-AC52-07NA27344. 


\section{Synergistic Effects of Turbine Wakes and Atmospheric Stability on Power Production at an Onshore Wind Farm}

Sonia Wharton ${ }^{1}$, Julie K. Lundquist ${ }^{2,3}$ and Nikola Marjanovic ${ }^{1,4}$

${ }^{1}$ Atmospheric, Earth and Energy Division, Lawrence Livermore National Laboratory, Livermore, CA

${ }^{2}$ Dept. Atmospheric and Ocean Sciences, University of Colorado, Boulder

${ }^{3}$ National Renewable Energy Laboratory, Golden, CO

${ }^{4}$ Civil and Environmental Engineering, University of California, Berkeley

\section{Introduction}

This report examines the complex interactions between atmospheric stability and turbine-induced wakes on downwind turbine wind speed and power production at a West Coast North American multiMW wind farm. Wakes are generated when the upwind flow field is distorted by the mechanical movement of the wind turbine blades. This has two consequences for downwind turbines: (1) the downwind turbine encounters wind flows with reduced velocity and (2) the downwind turbine encounters increased turbulence across multiple length scales via mechanical turbulence production by the upwind turbine. This increase in turbulence on top of ambient levels may increase aerodynamic fatigue loads on the blades and reduce the lifetime of turbine component parts. Furthermore, ambient atmospheric conditions, including atmospheric stability, i.e., thermal stratification in the lower boundary layer, play an important role in wake dissipation. Higher levels of ambient turbulence (i.e., a convective or unstable boundary layer) lead to higher turbulent mixing in the wake and a faster recovery in the velocity flow field downwind of a turbine. Lower levels of ambient turbulence, as in a stable boundary layer, will lead to more persistent wakes.

The wake of a wind turbine can be divided into two regions: the near wake and far wake (Vermeer et al. 2003), as illustrated in Figure 1. The near wake is formed when the turbine structure alters the shape of the flow field and usually persists one rotor diameter (D) downstream. The difference between the air inside and outside of the near wake results in a shear layer. This shear layer thickens as it moves downstream and forms turbulent eddies of multiple length scales. As the wake travels downstream, it expands depending on the level of ambient turbulence and meanders (i.e., travels in non-uniform path). Schepers (2003) estimates that the wake is fully expanded at a distance of $2.25 \mathrm{D}$ and the far wake region begins at 2-5 D downstream. The actual distance traveled before the wake recovers to its inflow velocity is dependent on the amount ambient turbulence, the amount of wind shear, and topographical and 
structural effects (Sanderse 2009). The maximum velocity deficit is estimated to occur at 1-2 D but can be longer under low levels of ambient turbulence (Ainslie 1988).

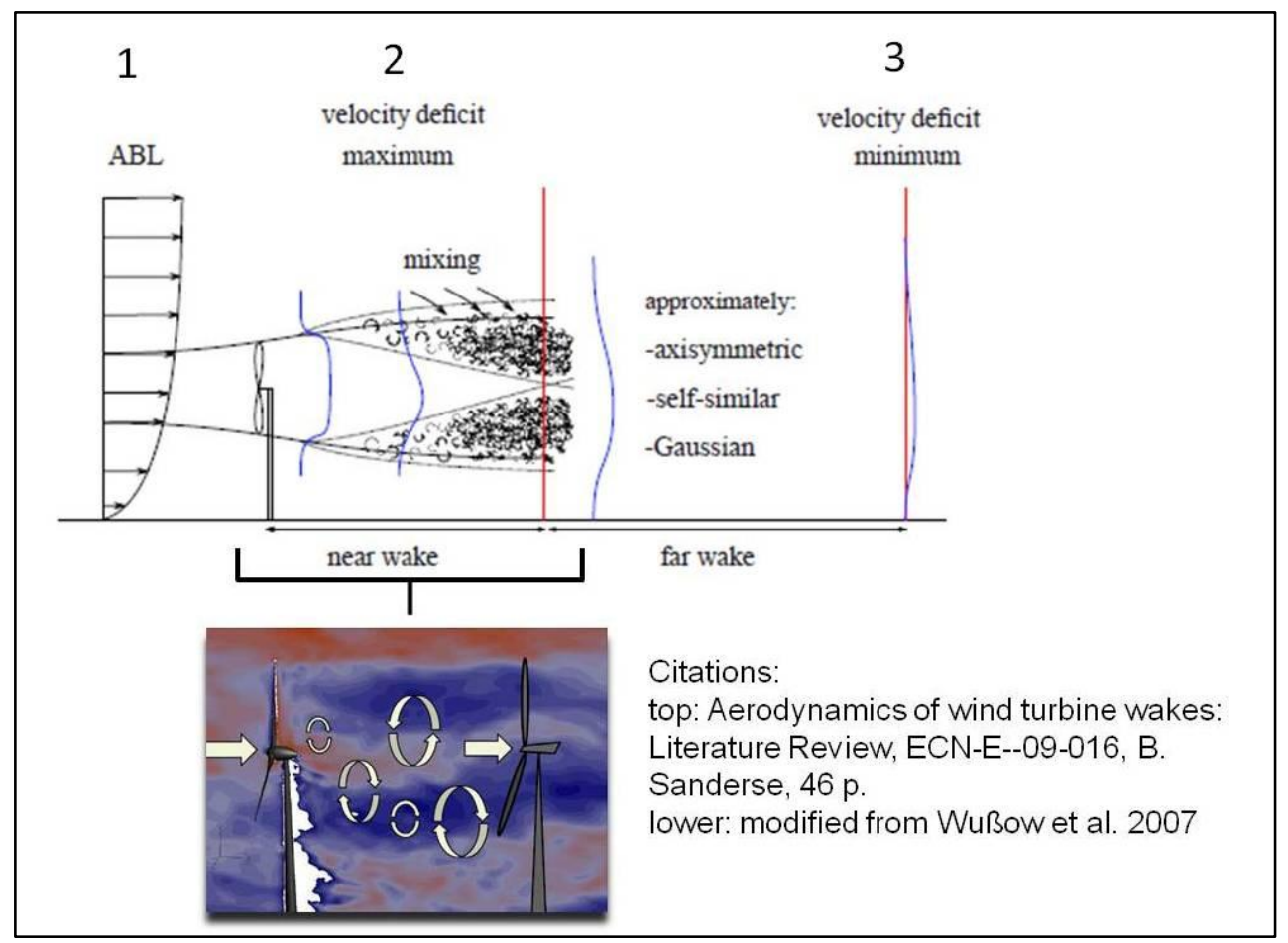

Figure 1: Schematic of a turbine wake showing (1) the vertical profile of wind speed in the atmospheric boundary layer prior to turbine energy extraction, "i.e., inflow conditions", (2) the velocity deficit maximum and increased turbulence downwind of the turbine, "i.e., near wake conditions", and (3) the velocity deficit and laminar flow recovery further downwind of the turbine, "i.e., far wake conditions". The lower figure is a numerical model simulation of the near wake region showing increased turbulent mixing induced by the upstream turbine wake and reduction in wind velocity behind the upwind turbine.

Our understanding of turbine wakes comes from wind tunnel experiments (e.g., Chamorro and Porte-Agel 2009), field experiments (e.g., Neustadter and Spera 1985, Elliott 1991, Conzemius 2010, Schepers et al. 2012), numerical simulations (e.g., Ainslie 1988, Dahlberg et al. 1991, Schepers 2003, Zahle and Sørensen 2008, Barthelmie et al. 2009, Porte-Agel et al. 2011, Politis et al. 2012), and from studies utilizing both experimental and modeling methods (e.g., Barthelmie and Jensen 2010). It is well documented that downwind turbines in multi-Megawatt wind farms often produce less power than upwind turbine rows (Neustadter and Spera 1985, Elliott 1991, Barthelmie et al. 2009, Barthelmie and Jensen 2010). These wake-induced power losses have been estimated from $5 \%$ to up to $40 \%$ depending on the turbine operating settings (e.g., thrust coefficient), number of turbine rows, turbine size (e.g., rotor diameter and hub-height), wind farm terrain, and atmospheric flow conditions (e.g., ambient wind speed, turbulence, and atmospheric stability) (Sanderse 2009). 
Early work by Elliott and Cadogan (1990) suggested that power data for different turbulent conditions be segregated to distinguish the effects of turbulence on wind farm power production. This may be especially important for downwind turbines within wind farms, as chaotic and turbulent wake flows increase stress on downstream turbines (Mann et al. 2008). Impacts of stability on turbine wakes and power production have been examined for a flat terrain, moderate size (43 turbines) wind farm in Minnesota (Conzemius 2010) and for an offshore, 80 turbine wind farm off the coast of Denmark (Hansen et al. 2012). Conzemius (2010) found it difficult to distinguish wakes (i.e., downwind velocity deficits) when the atmosphere was convective as large amounts of scatter were present in the turbine nacelle wind speed data. This suggested that high levels of turbulence broke-up the wake via large buoyancy effects, which are generally on the order of $1 \mathrm{~km}$ in size. On the other hand, they found pronounced wake effects when the atmosphere was very stable and turbulence was either suppressed or the length scale was reduced as turbulence in this case was mechanically produced (i.e., friction forces). This led to larger reductions at downwind turbines and maximum velocity (power) deficits reached up to $50 \%$ (70\%) during strongly stable conditions. At an offshore Danish wind farm, Hansen et al. (2012) found a strong negative correlation between power deficit and ambient turbulence intensity (i.e., atmospheric stability). Under convective conditions, when turbulence levels were relatively high, smallest power deficits were observed. Power deficits approaching 35 to $40 \%$ were found inside the wind farm during stable conditions.

\section{Methods}

\subsection{Wind and power observations}

Turbine power data from July 2007 to June 2008 were collected at a multi-MW wind farm in western North America. Strong land-ocean temperature differences, particularly during the summer months, drive strong local southwesterly winds at the site. The landscape is not flat; instead, the local area and immediate fetch is grass-covered rolling hills, with elevation changes of less than $150 \mathrm{~m} .80 \mathrm{~m}$ tall, horizontal-axis, three-bladed wind turbines, with rotor diameters of approximately $80 \mathrm{~m}$ are located at the wind farm. The turbines generate power based on the wind between $40 \mathrm{~m}$ and $120 \mathrm{~m}$ above ground level (AGL). Hub-height $(80 \mathrm{~m}$ ) wind speed was measured with cup anemometers (IceFree3, NRG Systems, Hinesburg, VT, USA) located downwind of each turbine's nacelle hub. The free stream wind direction was determined using a wind vane (NRG \#200) mounted at a height of $77 \mathrm{~m}$ on an $80 \mathrm{~m}$ tall meteorological tower. Measurements from a three beam, $4500 \mathrm{~Hz}$ Doppler mini Sonic Detection and Ranging (SODAR) (Mode14000, Atmospheric Systems Corporation, Santa Clarita, CA, USA) provided wind speed and direction every $10 \mathrm{~m}$ from $20 \mathrm{~m}$ to $200 \mathrm{~m}$ AGL. All meteorological and power 
measurements were 10-minute averages. The stability parameters were derived from a combination of SODAR and meteorological tower data (see Section 2.2).

A map of the wind farm and summer-time wind direction observations is shown in Figure 2.

Previous work by Wharton \& Lundquist (2012a) showed that wind direction within the wind farm varies little with height across the rotor disk for any 10-minute period. We took advantage of the lack of direction shear and persistent onshore flow conditions and selected two areas of wind turbines in the northern and southern sections of the wind farm for wake analysis. The first subset, the North cluster, contained three rows of turbines, numbered 1(upwind) to 3(downwind). The second subset, South cluster, contained only two rows: row 1 (upwind) and row 2 (downwind) (Fig. 2). The turbines in each cluster were carefully selected so that no turbine was more than $10 \mathrm{~m}$ in elevation from any other turbine within the cluster. The turbines in row 1 were also selected to ensure that they did not experience wakes from upwind hills or other obstacles, i.e., the distance between an upwind obstacle and downwind turbine was verified to ensure that the turbine was no closer than four rotor diameters (IEC 2003).
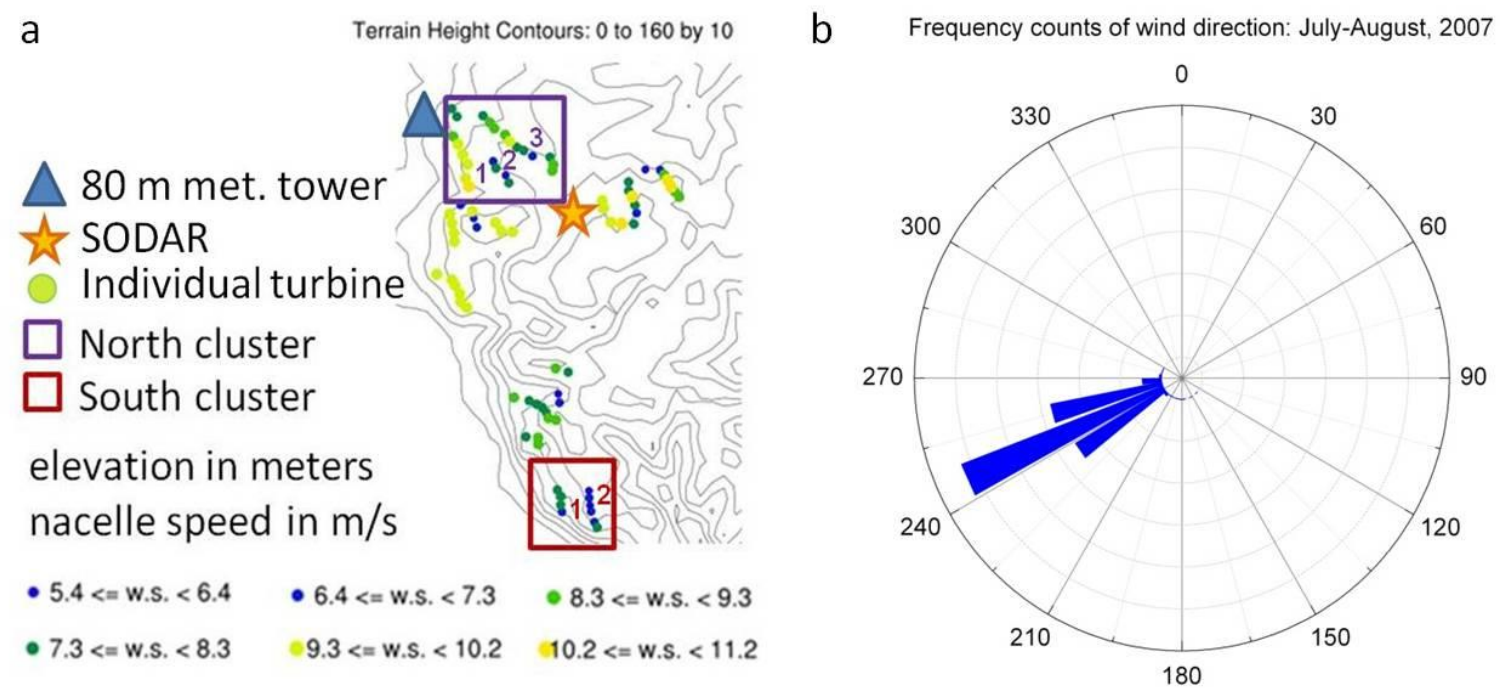

Figure 2: (a) layout of the wind farm showing a July snap-shot of turbine nacelle wind speed observations (magnitude according to color), subset of North and South turbine clusters and rows, upstream $80 \mathrm{~m}$ tall meteorological tower, and SODAR. (b) wind rose of $77 \mathrm{~m}$ height wind direction data illustrating the strong summer-time (July and August) direction dominance around 240 degrees (westsouthwest) as measured by the $80 \mathrm{~m}$ meteorological tower.

The amount of power theoretically available to a turbine, at time $i$, is expressed as the energy flux $\left(P_{i}\right.$, Watts): 


$$
P_{i}=0.5 \rho_{a} A_{t} C_{p} U_{i}^{3}
$$

where, $\rho_{a}$ is the air density $\left(\mathrm{kg} \mathrm{m}^{-3}\right), A_{t}$ is the area of a turbine rotor disk $\left(\mathrm{m}^{2}\right), C_{p}$ is the turbine efficiency, and $U_{i}$ is the full rotor-disk wind speed $\left(\mathrm{m} \mathrm{s}^{-1}\right)$, if available, or nacelle wind speed $\left(\mathrm{m} \mathrm{s}^{-1}\right)$ averaged over a time period of interest (here, 10-minutes). Power performance by a turbine row was evaluated using a normalized power expression, where $P_{\text {rowl }, i}$ is the average power output of the upwind turbines (i.e., represents the free stream power generation) and $P_{\text {row }, i}$ is the average power of the downwind turbines, where $x$ is turbine row 2 (South Cluster) or row 2 or row 3 (North Cluster).

$$
P_{\text {norm }}=\frac{P_{\text {row }, i}}{P_{\text {rowx }, i}}
$$

As shown in Eq (2), the downwind turbines are normalized by the first upwind turbine row, such that row1 always has a $P_{n o r m}$ value of 1 . A power deficit is observed when $P_{\text {norm }}$ is less than 1 for turbines in row 2 or $3 . P_{n o r m}$ was calculated collectively for each row for every 10 minute period $(i)$ when the nacelle wind speed was greater than the cut-in speed $\left(U_{i}>3.5 \mathrm{~m} / \mathrm{s}\right)$ at all turbines within a turbine cluster. A normalized nacelle wind speed $\left(U_{\text {norm }}\right)$ for row 2 and 3 was calculated in a similar manner as $P_{n o r m}$,

$$
U_{\text {norm }}=\frac{U_{\text {row1 }, i}}{U_{\text {row }, i}}
$$

\subsection{Atmospheric stability classification}

In earlier works, the influences of atmospheric stability on ambient wind speed and turbulence at rotor-disk heights (Wharton and Lundquist 2010, 2012a) and on upwind turbine power performance (Wharton and Lundquist 2010, 2012b) were found to be significant at this wind farm. Atmospheric stability conditions at the wind farm were determined using a combination of on-site, SODAR-derived stability parameters, including turbulence kinetic energy $(T K E)$, vertical turbulence intensity $\left(I_{w}\right)$, horizontal turbulence intensity $\left(I_{U}\right)$, and the wind shear coefficient $(\alpha)$. The on-site parameters were validated against the more robust estimate of stability, the Obukhov length $(L)$, using a nearby research station 3-dimensional sonic anemometer. The complete methodology and details can be found in Wharton and Lundquist (2012a). In brief, the SODAR-based horizontal turbulence intensity was found to be a well suited parameter for estimating turbulence at the wind farm because of its high accuracy (as compared to $L$ ) and high data availability. In the current study, we use $I_{U}$ to classify 10 -minute time periods as being either stable $\left(I_{U}<10 \%\right)$, neutral $\left(10 \%<I_{U}<13 \%\right)$, or convective $\left(I_{U}>13 \%\right)$. A stable atmosphere at the wind farm usually resulted in higher wind speeds at the top of the turbine rotor disk (e.g., higher wind shear) and low turbulence intensity within the rotor disk. Small amounts of wind shear and high 
turbulence intensity magnitudes were observed during convective regimes. In the summer months, daytime hours were generally convective, nighttime hours stable, and near-dawn and near-dusk transitions were neutrally stable.

\subsection{Wake identification}

After considering the layout of the wind farm, turbine-induced wakes were presumed to occur when the wind was from $245 \pm 15$ degrees at the North Cluster and from $270 \pm 15$ degrees at the South Cluster. This put the turbines in row 2 directly in the wake of row 1 (Clusters North and South), and row 3 directly in the wake of rows 1 and 2 (North Cluster). In the northern cluster, turbines in row 2 were approximately 8 rotor diameters $(\sim 640 \mathrm{~m})$ from upwind turbines in row 1 , while turbines in row 3 where approximately $6 \mathrm{D}(\sim 480 \mathrm{~m})$ from row 2 , and $14 \mathrm{D}$ from row $1(1.1 \mathrm{~km})$. In the southern cluster, row 2 was approximately $9 \mathrm{D}(\sim 720 \mathrm{~m})$ downwind of row 1 . Turbines used in this analysis were selected so that all turbines in either cluster were no more than $10 \mathrm{~m}$ in elevation to minimize nacelle wind speed and power differences due to wind shear. A more exact wake identification process would require highresolution, 3-dimensional (3-D) wind field data such as from a scanning Light Detection and Ranging (LIDAR) remote platform (e.g., Käsler et al. 2009, Pichugina et al. 2011). Scanning LIDARs measure wind speed, direction and turbulence in both the vertical and horizontal fields unlike the SODAR unit used here which measured only the vertical field.

\section{Results}

\subsection{Upwind turbines: effects of stability on wind and power}

As shown in detail in Wharton and Lundquist (2012a, 2012b), stability conditions had a significant impact on the ambient wind speed and turbulence vertical profiles and power generation at upwind (row 1) turbines during the spring and summer months. During stable conditions, wind shear was high, positive, and wind speeds at the top of the rotor disk $(120 \mathrm{~m})$ were on average $20 \%$ higher than at hub-height $(80 \mathrm{~m})$. In contrast, during convective conditions, wind shear was low and often negative; wind speeds at the top of the rotor disk were lower on average than at hub-height (Fig. 3a). In Figure 3, the predicted wind profile (based on the basic power law) is also shown. The power law was based on a wind shear parameter of 0.17 (i.e., expected conditions during a neutral atmosphere). During observed neutral conditions at the wind farm, the measured wind profile was nearly identical to the "expected profile". This indicates both the utility and accuracy of the derived stability parameters found in Wharton 
and Lundquist (2012a) and the accuracy of the SODAR measurements. In Figure 3, as well as in Figures $5-8$, atmospheric stability was determined using the stability parameter, $I_{U}$.
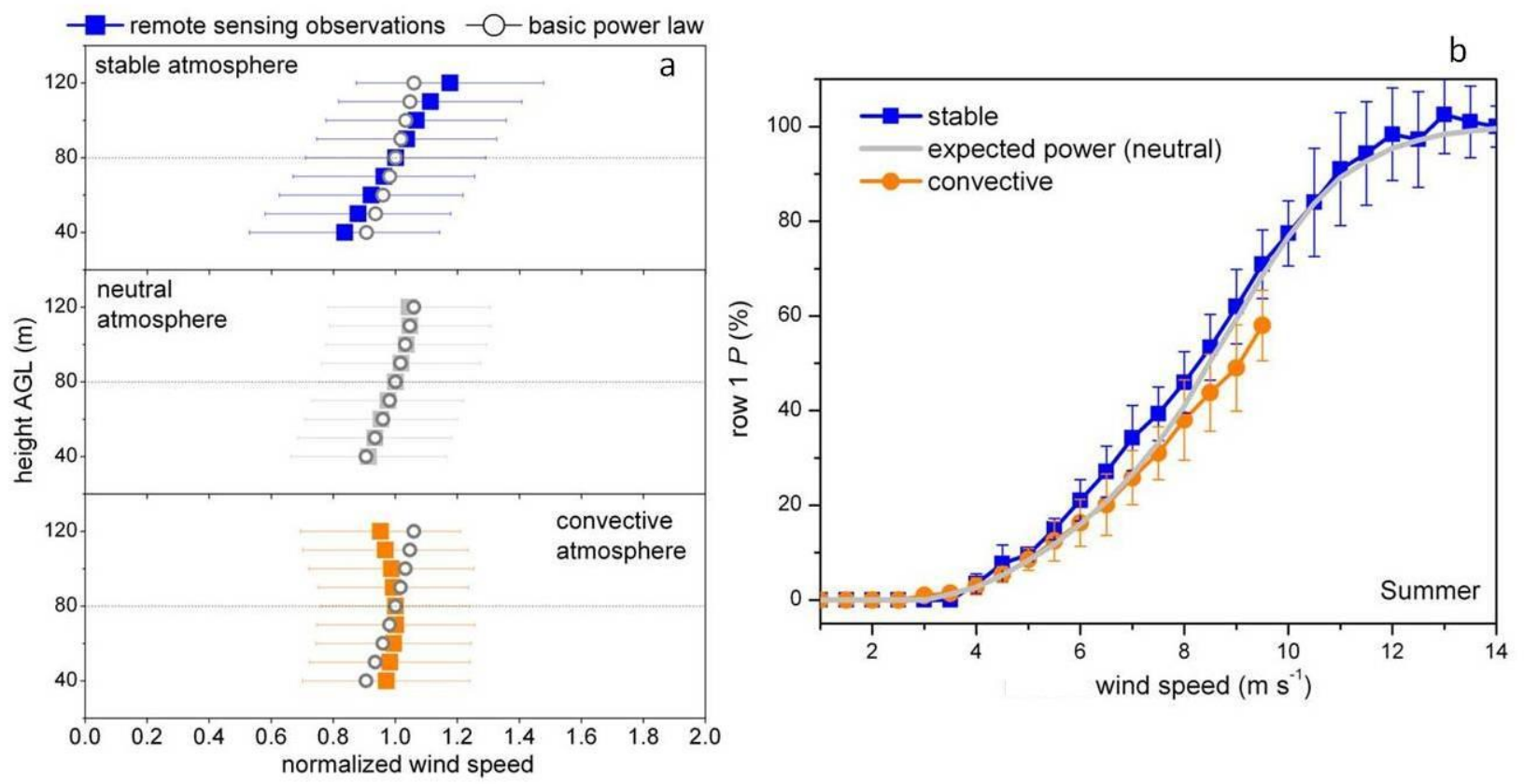

Figure 3: (a) normalized vertical profiles of SODAR wind speed from $40 \mathrm{~m}$ (equivalent to the bottom of the rotor disk) to $120 \mathrm{~m}$ (top of rotor disk) according to stability regime during the summer months. The profiles are normalized by hub-height $(80 \mathrm{~m})$ wind speed. Also plotted is the expected wind speed profile as predicted by the basic power law (see Wharton and Lundquist 2012a). (b) power curves for row 1 turbines, segregated by stability regime, show strong power distinctions. The wind speed on the $x$-axis is a "true-flux" equivalent wind speed and represents conditions across the entire rotor disk (see Wharton and Lundquist 2012b).

Stable atmospheric conditions led to higher wind speeds at heights equivalent to the top of rotor disk (100 to $120 \mathrm{~m}$ AGL), lower ambient turbulence levels, and higher power performance in the upwind turbines than during any other stability regime. Power performance during stable conditions was up to $15 \%$ higher than during convective conditions when turbine power was plotted as a function of the "trueflux" equivalent wind speed (Fig. 3b). The equivalent wind speed includes measurements of wind shear (in the vertical field) and turbulence. This wind speed was used in the power curves (Fig. 3b) because the SODAR profiles show that these variables are influenced by stability (Fig. 3a) (see Wharton and Lundquist $2012 \mathrm{~b}$ for more discussion). The greatest stability-influenced power differences occurred at wind speeds above $9 \mathrm{~m} / \mathrm{s}$. Underperformance (power generation below the expected amount) was observed during convective conditions for all wind speeds above $7.5 \mathrm{~m} / \mathrm{s}$. The "expected" power curve in Figure $3 b$ is based on the manufacturer's power data and neutral conditions. 


\subsection{Cluster turbines: average effects of turbine wakes on downwind power}

To distinguish the effects of turbine wakes on downwind hub-height wind speed and power generation, we examined these variables regardless of stability condition for wind sectors which presented "likely" wake events. The direction sectors were determined by the layout of the wind farm (see Section 2.3). Figure 4 shows average normalized power production (top panel) and average normalized wind speed (bottom panel) for turbines in the (a) North and (b) South turbine clusters over a two month period.
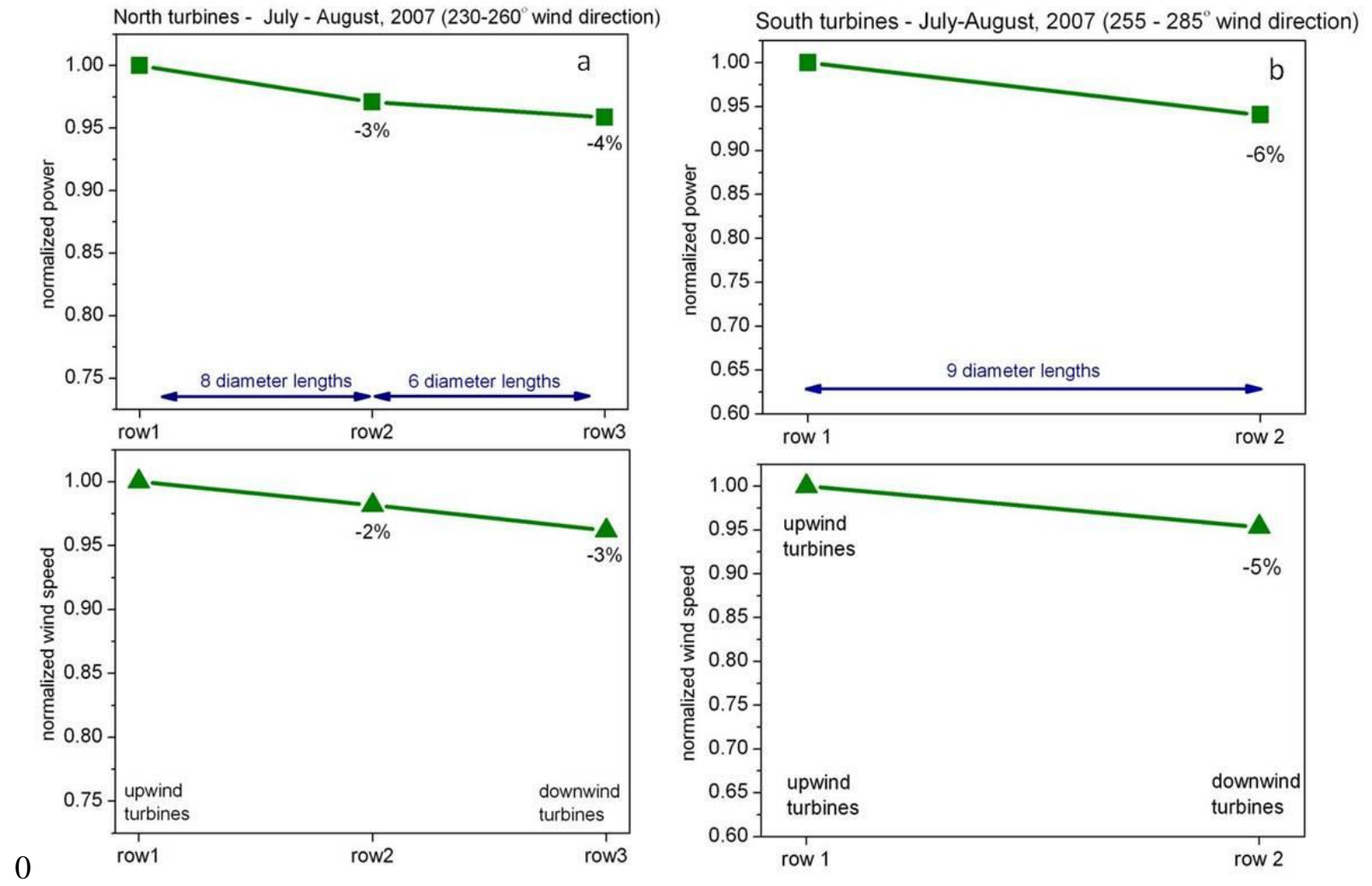

Figure 4: Normalized power output (top panel) and wind speed (lower panel) in the (a) North cluster and (b) South cluster. These plots show wake effects up to -6\% in downwind turbine power output. Averages are based on the 10-minute measurements in July and August (regardless of stability) and the wake determination criteria described in Section 2.3.

Over the two month period, North cluster turbines in row 2 and 3 had on average lower hubheight wind speeds and power generation than the upwind turbines in row 1 (Fig. 4a). The largest power and wind speed deficiencies between two rows were observed between row 1 and 2. Power deficiencies reached $3 \%$ between row 1 and 2 ( $8 \mathrm{D}$ distance) in the North Cluster. Between row 2 and row 3 (6 D distance), a smaller deficiency was observed (1\%). Slightly larger wind speed and power deficiencies were observed at the southern end of the wind farm (Fig. 4b) and approached $6 \%$ for power and $5 \%$ for 
hub-height wind speed in row 2 versus row 1 ( $9 \mathrm{D}$ distance). Total power deficiencies in the Southern Cluster were almost twice those observed in the northern end of the wind farm even though North Cluster had an additional row of downwind turbines. Although the two month average deficiencies are relatively small, a trend towards lower wind speeds and power generation in downwind turbine rows was consistent.

\subsection{Cluster turbines: effects of turbine wakes and atmospheric stability on downwind power}

Wind direction was not influenced by stability regime during the summer months at this wind farm. This allowed for the analysis of wake effects under different stability regimes (stable, near-neutral, and convective) without the added effect of direction variability. The two month 10-minute wind speed and power generation measurements were segregated by atmospheric stability during "likely" wake events in Figure $5 \mathrm{~b}$. The conditions regardless of stability are shown in the left hand panel for direct comparison. These are the same data as found in Figure 4a. Small but perceptible stability effects on

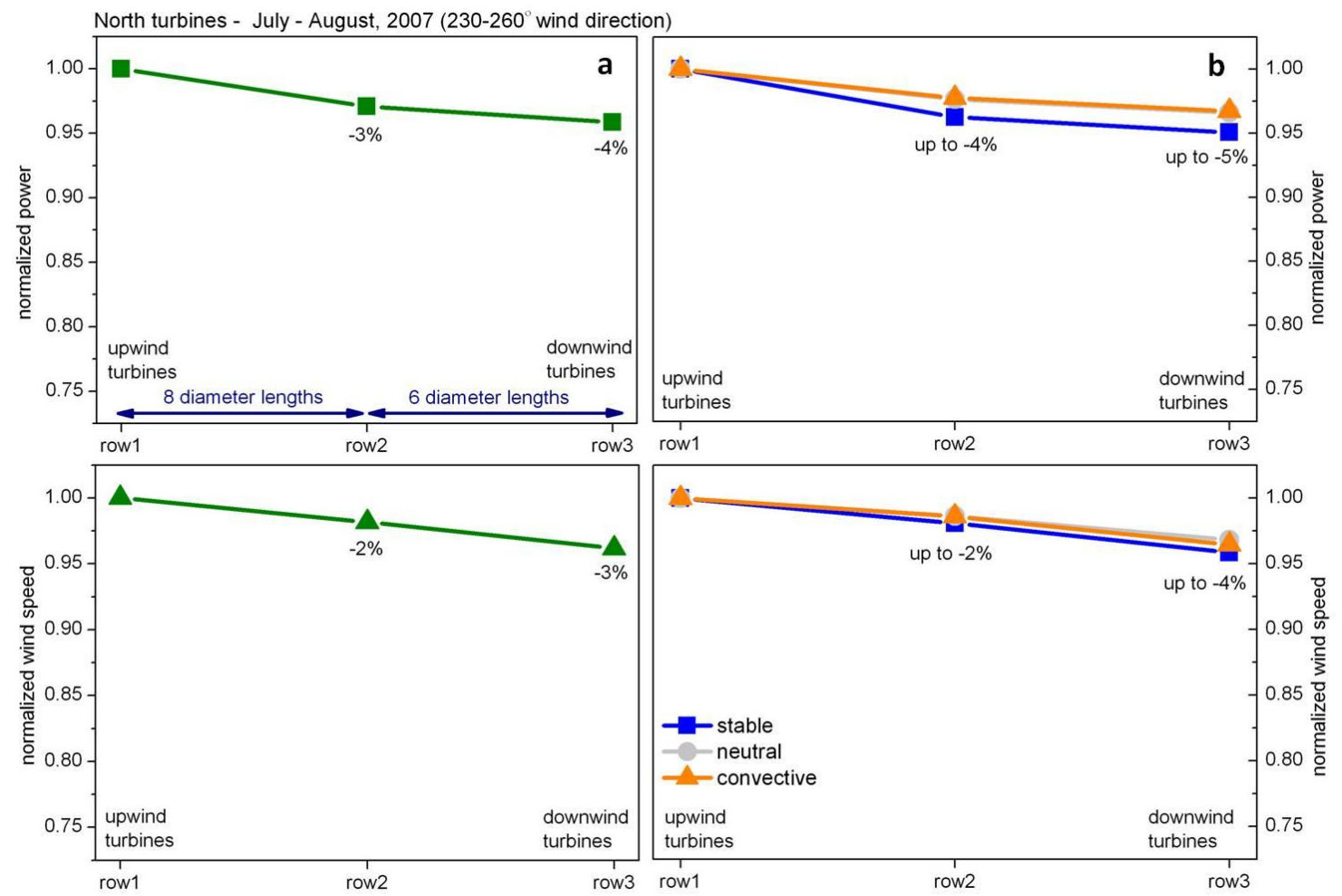

Figure 5: Two month average normalized power output (top panel) and wind speed (lower panel) during (a) all stability conditions and (b) segregated by stability class (stable, neutral or convective) at the North cluster turbines for July and August in 2007. Compared to the two day event in May 2008 (Figure 6), power losses and wind speed deficiencies averaged less over the longer time period $4 \%$ here versus $19 \%$ during the May event). Even so, the pattern of highest losses during stability conditions remained a consistent feature in the downwind turbine rows. 
downwind power production and nacelle wind speed are apparent in the North Cluster. Power losses were up to $5 \%$ during stable conditions as compared to power losses of only $3 \%$ during connective and neutral conditions (Fig. 5b). Figure 5 illustrates average wake effects over a two month period. In order to see if individual days had stronger wake effects, we isolated a three day period in May that had noticeably larger power and wind speed deficiencies in row 2 and 3. Figure 6a shows the downwind power and wind speed losses during all stability classes, while figure $6 \mathrm{~b}$ shows the same measurements segregated by atmospheric stability. Two things are clear in this figure: (1) Wake effects on a daily time scale can be much greater than the monthly averages. Here, power deficiencies reached $19 \%$ when atmospheric stability was not taken into account. (2) Atmospheric stability exaggerates wake effects on a daily time scale. For two days in May, power losses reached 16\% in row 2 and 24\% in row 3 during stable conditions. During convective conditions the losses were $13 \%$ and $15 \%$, respectively, for both rows. We found that power losses were more exaggerated between row 2 and row 3 during stabile conditions than during neutral and convective conditions. This suggests that the wake persisted farther downstream during stable conditions and maximum velocity deficits at the downwind turbines were larger.

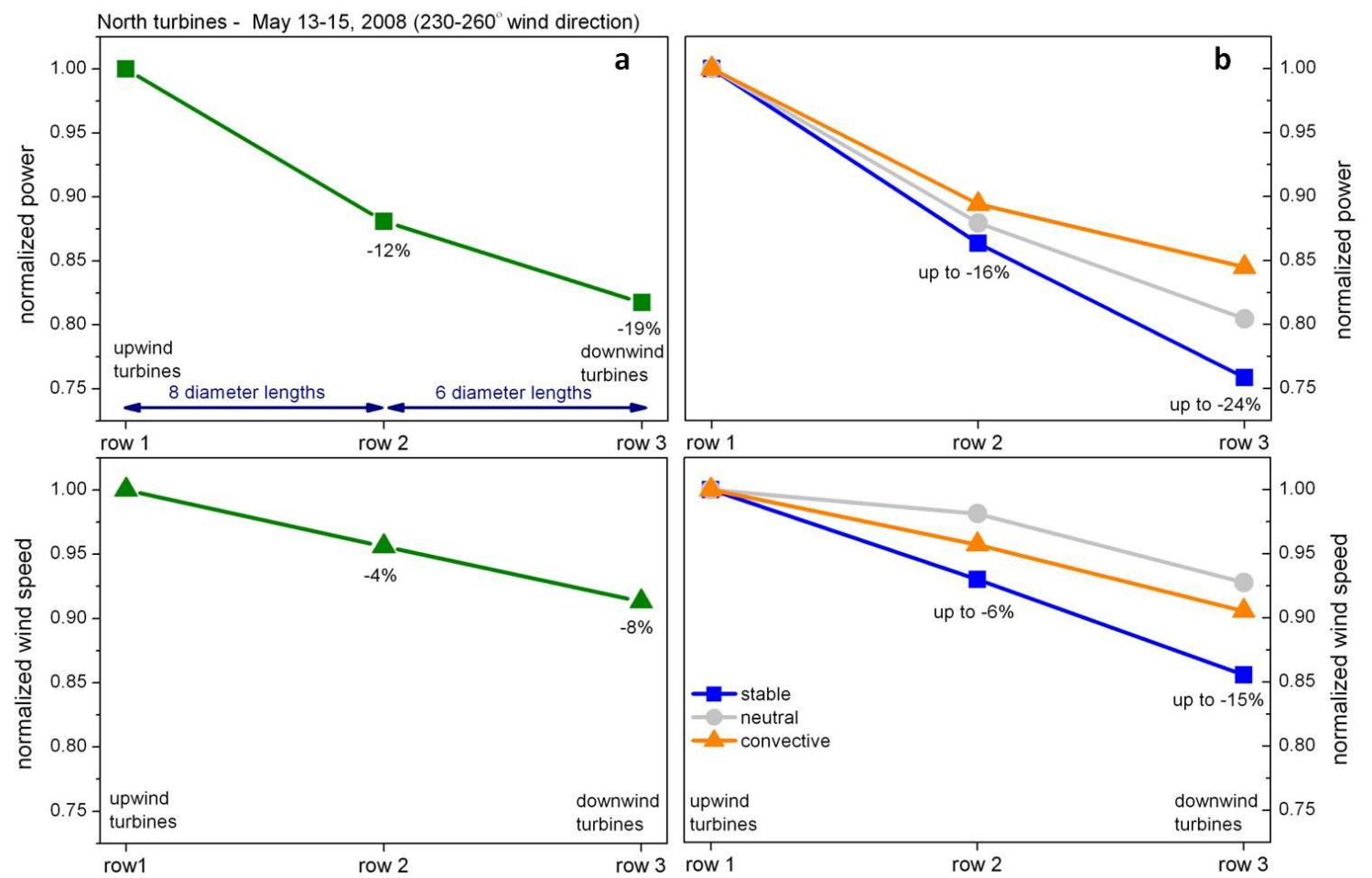

Figure 6: Normalized power output (top panel) and wind speed (lower panel) during (a) all stability conditions and (b) segregated by stability class (stable, neutral or convective) at the North cluster turbines for two days in May 2008. Without considering stability the average power loss reaches $19 \%$ for turbines in row 3. The power deficit is not uniform for all stability regimes: power losses reached $24 \%$ during stable atmospheric conditions compared to a loss of only $16 \%$ during convective conditions. 
In June and July, average power losses at the North Cluster reached 5\% when stability was considered (Fig. 5b), while slightly larger power deficits across the two month period were observed at the southern end of the wind farm (Fig. 7). At the South Cluster, power deficits equaling 6\% and wind speed deficits of $5 \%$ were observed in row 2 when all stability classes were considered over the two month period (Fig. 7a). After segregating the data for stability, even larger deficits were found. During stable conditions, power losses reached $8 \%$ at the downwind turbines (Fig. 7b).

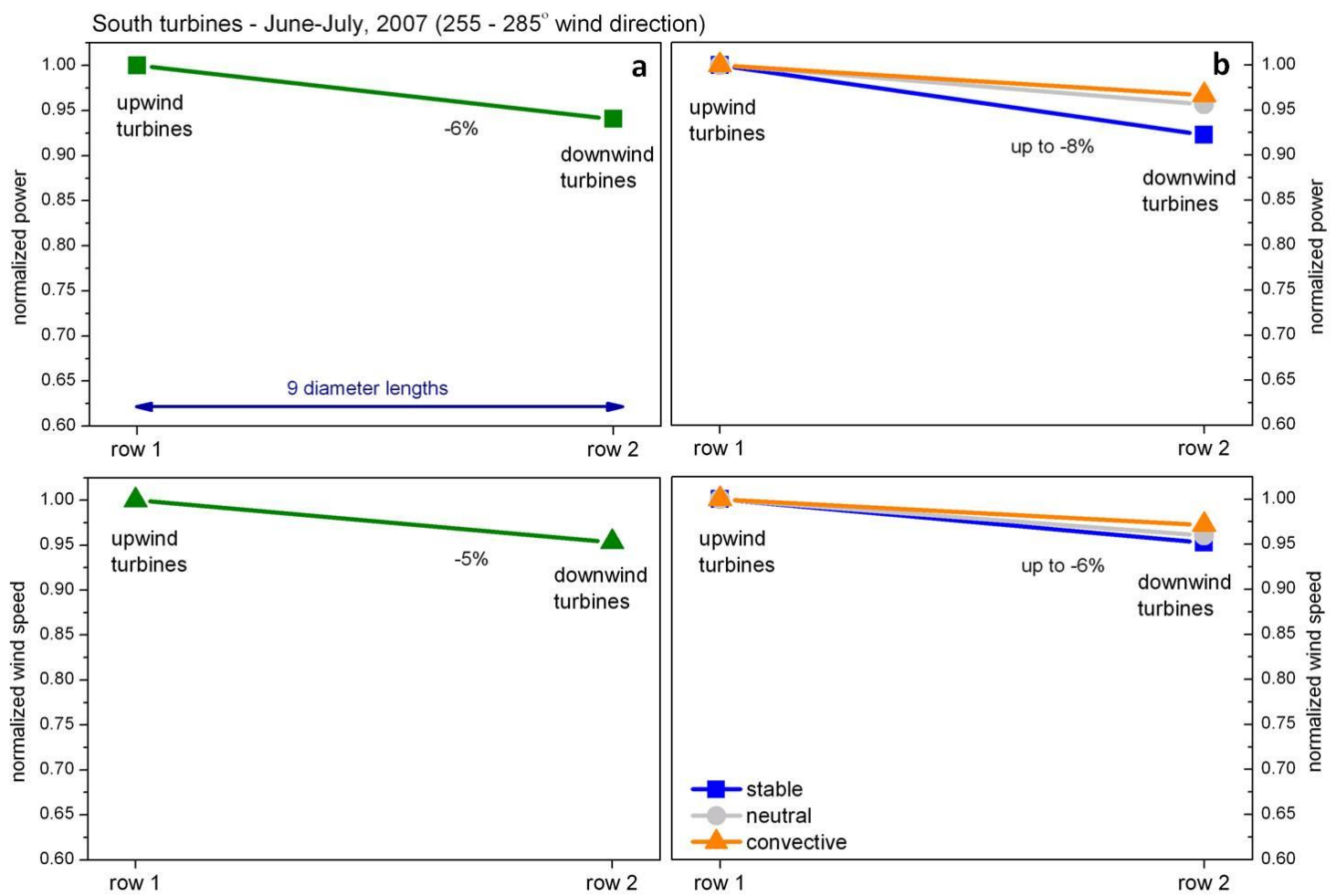

Figure 7: Two month average normalized power output (top panel) and wind speed (lower panel) during (a) all stability conditions and (b) segregated by stability class (stable, neutral or convective) at the South cluster turbines for July and August in 2007. Compared to the two day event in May 2008 (Figure 8), power losses and wind speed deficiencies averaged less over the longer time period (6\% here versus $21 \%$ during the May event). Even so, the pattern of highest losses during stability conditions remained a consistent feature in the downwind turbine rows and power losses were double (8\%) during stable conditions than they were during convective conditions (4\%).

The effects of wakes and stability were also examined at the southern end of the wind farm for the three day period in May. The largest power deficits were observed in this cluster. Power losses of $32 \%$ were measured during stable conditions at the downwind turbines. This resulted from a $14 \%$ loss in wind speed. During stable conditions the power losses were double those measured during convective conditions. These data confirm that stable conditions result in the strongest wake effects across the wind farm. 


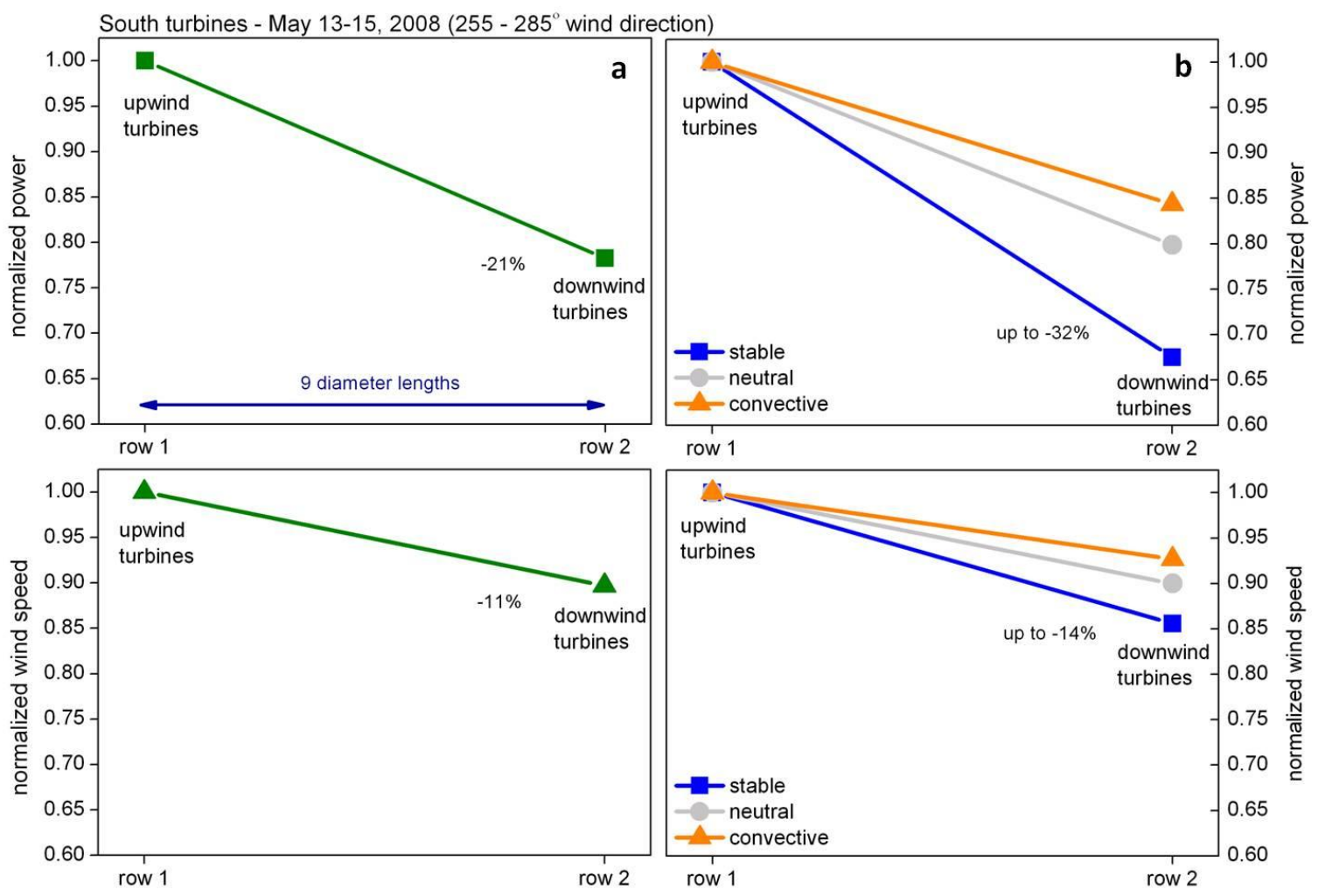

Figure 8: Normalized power output (top panel) and wind speed (lower panel) during (a) all stability conditions and (b) segregated by stability class (stable, neutral or convective) at the South cluster turbines for two days in May 2008. Without considering stability the average power losses reached $21 \%$ for turbines in row 3. The power deficit is not uniform for all stability regimes: power deficits reached $32 \%$ during stable atmospheric conditions compared to a loss of only $17 \%$ during convective conditions.

\section{Discussion}

As both onshore and offshore wind farms are expanding in size, most turbines within a wind farm are downwind of at least one row of upwind turbines. This causes them to be almost continuously located in turbine wakes. The situation may be even more complex as multiple wakes can merge deep within wind farms and significantly change the characteristics of the wind flow (e.g, "deep array effect"). From both observations and modeling simulations, wakes are known to cause a decrease in power production through velocity deficits, although the exact understanding of wake physics and interactions with downwind turbines (e.g., rotor-scale response) is not known. Few studies have been able to capture information about the two- and three-dimensional flow fields of wind speed, direction, and turbulence, as well as how these atmospheric variables affect fatigue loads (e.g., stress on the blades) and turbine thrust coefficients. In Wharton and Lundquist (2012b) we examined the influences of ambient turbulence and wind shear on power production in the leading row of turbines at the same wind farm as discussed here. 
The present study looked at downwind power and wind speed measurements in up to two downwind rows at the north and south boundaries of the wind farm. We also examined the same turbines under ambient periods of high mixing (convective), low mixing (stable), and near-neutrality to see if atmospheric stability had any influence on wake effects.

In order to determine the wind directions which would lead to "likely" wake events, we first examined the power and wind speed data at both upwind and downwind turbines. The data were normalized by the first row of turbines, row 1, as we were looking for power and wind speed losses in rows 2 and 3. This methodology allowed for downwind turbines to either produce more electricity or have higher wind speeds (i.e., those data were not screened out), but after careful data analysis we found that power and velocity deficits downwind during wake events were always present. Our data analysis included a careful treatment of wind direction and selection of turbines so that all turbines within a cluster were no more than $10 \mathrm{~m}$ in elevation. We also focused on spring and summer time periods because earlier work (Wharton and Lundquist 2012a) found that stability effects on the wind speed profile and turbulence profile were strongest during these time periods. Wharton and Lundquist (2012b) furthermore found strong stability effects on power generation during these months at the upwind row of turbines.

Our wind direction criterion ( \pm 15 degrees) was larger than other studies have used. Hansen et al. (2012) used a 5 degree wind direction bin for their wake analysis at the Horns Rev offshore wind farm. Horns Rev is evenly grid-spaced with $7 \mathrm{D}$ turbine spacing. They found that quantification of wake effects was hampered by the lack of observations in a particular direction bin and this resulted in high scatter in the observations for certain direction sectors. After careful study of our wind farm layout and the wind rose, we decided to use a \pm 15 degree wind direction criterion ( $245 \pm 15$ degrees at the North and $270 \pm 15$ degrees at the South Cluster). This eliminated the problem of high scatter as found in Hansen et al. (2012) who averaged over small sample sizes. It also seemed appropriate to have a larger wind sector at our site for "likely" wake events since the turbines are not uniformly distributed across a grid. Instead, the turbines are sited in roughly parallel rows along hill tops (Fig. 2).

Even in grid-spaced wind farms, power deficiencies are not uniform. Hansen et al. (2012) and Schepers et al. (2012) report significantly larger power deficits between the first and second row of turbines while the remaining downstream power deficits were less. We saw a similar effect in the North Cluster where the largest power and wind speed deficiencies were between row 1 and row 2 while smaller losses were measured between row 2 and 3. For reference, the maximum velocity deficit is estimated to occur at 1-2 D but can be longer under low levels of ambient turbulence (Ainslie 1988). 
Although most of the literature report downwind power deficiencies on the order of 5-15\%, several studies have observed much larger wake effects. Power losses up to $-80 \%$ were observed during periods of very low turbulent mixing (i.e., stable atmosphere) at the Netherlands ECN Wind Turbine Test Site (Schepers et al. 2012). We also observed the strongest power and nacelle wind speed deficiencies during stable conditions, approaching $32 \%$. We found smaller but noticeable power and wind speed losses (up to 20\%) during convective and neutral conditions. In comparison, Hansen et al. (2012) observed little to no mean wind and power deficits when atmospheric conditions were near-neutral or convective in downwind turbines.

The size (i.e., scales) of turbulence, in addition to magnitude, is important in wind farms because of the destructive nature of certain turbulent structures on turbine structural loading. Scale is usually determined by isolating the maximum energy scale in the power spectrum. As wind speed fluctuations were studied here as perturbations from 10-minute averages, we were not able to isolate both high frequency turbulence (which could be analyzed from $1 \mathrm{~Hz}$ or faster data) or low frequency turbulence (which require a longer averaging period). More work needs to be done to address and quantify the uncertainty related to the scales of turbulence on power generation. In wind farms it is estimated that turbulence scales found in wakes are reduced to about half the free-stream conditions (Verheij et al. 1993, Tindal 1993). Furthermore, wake effects in non-flat terrain may be intensified as a high surface roughness increases atmospheric turbulence and causes it to become more isotropic (Petersen et al. 1998, Mann 2000, Silva Lopes et al. 2007). Some attempts to quantify these wake effects at wind farms in non-flat terrain have been made (Jimenez et al. 2011). Jimenez et al. report a shift towards higher turbulence frequencies in wakes at non-flat terrain sites. Although the effects of these turbulence shifts on power production in downwind turbines are not well understood and more research is needed.

In some locations, particularly the Great Plains, USA, strong bursts of turbulence at heights near the top of turbine rotors are a regularly occurring phenomena. These coherent structures are produced by strong shearing from nocturnal low-level jets and can be damaging to turbine rotor components (Kelley et al. 2001, Hand et al. 2003). The wind farm studied here does not appear to experience strong "topdowned" turbulence on stable nights as low-level jets are very infrequent. This likely explains why the leading row of turbines at this wind farm produced more power during stable conditions than when the atmosphere is convective as wind shear in stable conditions leads to higher wind speeds at the top of the rotor without also producing destructive turbulence scales. The effects of both wakes and stability are more complex as shown here and likely lead to smaller than expected wind farm power generation levels, at least within the two clusters examined, on stable nights. Although more work, including modeling, is 
needed in order to examine atmospheric conditions, e.g., wind shear and turbulence levels, across the entire wind farm.

\section{Future Work}

The "deep array effect" in large wind farms has caused the need for predicting the spatial distribution of wakes (e.g., meandering and merging wakes) and consequential power losses. Several modeling studies have looked at simulating downwind velocities within these farms. These include: the Ris $\varnothing$ WAsP model (Barthelmie and Jensen 2010), the MM5 model (Rooijmans 2004), and the RAMS model (Roy et al. 2004). More recently, attempts have been made to include wind turbine parameterizations in the Weather and Research Forecasting (WRF) model (Adams and Keith 2007, Fitch et al. 2011). Presently, the multi-agency (CUB, NREL, NOAA, LLNL) Turbine Wake and Inflow Characterization Study (TWICS) has begun to model inflow and wake conditions using WRF-LES (Pichugena et al. 2011).

To our knowledge, nearly all wake modeling and observational studies have previously examined wake effects in either uniformly grid-spaced wind farms or in research sites with few turbines available. The wind farm studied here allows us to examine how an irregular-spaced, multi-MW wind farm influences turbine wakes. Future work will involve using wind turbine parameterizations in WRF developed by Anna Fitch to model these effects across the entire wind farm. The Fitch et al. parameterization simulates wind turbines as a sink of momentum and source of turbulent kinetic energy and has been tested on idealized wind farm configurations (Fitch et al. 2011). Initial WRF simulations have been run for this site without implementation of the turbine parameterization schemes (Marjanovic 2011, Marjanovic et al. 2011, Wharton et al. 2011). Figure 9 shows the WRF simulations of hub-height wind speed across the wind farm compared to the interpolated nacelle wind speed observations for three 10-minute periods, each with distinct stability conditions on July 5, 2007. The WRF simulations are able to capture spatial variability across the $6 \mathrm{~km} \mathrm{X} 10 \mathrm{~km}$ wind farm. Both the wind speed magnitudes and range of variability agree well with the observations for both the stable and near-neutral cases while less agreement is found for the convective case. Also, in comparison to the observations, the WRF simulations do not show a trend in lower wind speeds within the wind farm; instead wind speed increases are modeled for the downwind turbines. These simulation runs show the complexity of modeling wakes and the need for additional observation-modeling wake studies, particularly for wind farms in non-flat terrain and for sites which have large stability effects on power generation. 

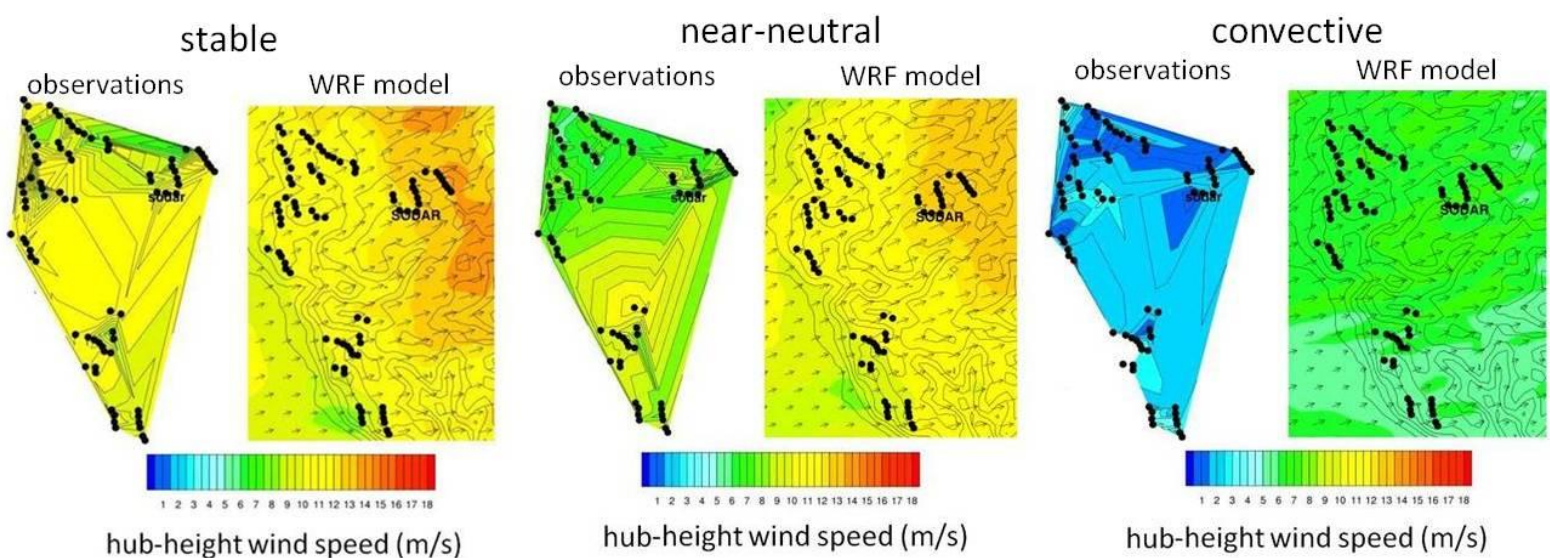

Figure 9: Snap-shot of interpolated hub-height $(80 \mathrm{~m})$ nacelle wind speed observations in comparison to simulated hub-height wind speeds for the three major stability classes. The black dots show the locations of individual turbines. Model simulations were made using the Weather and Research Forecasting (WRF) model without a wind turbine parameterization (see Wharton and Lundquist 2011 for details on the WRF analysis). The WRF simulations also show the modeled wind direction vectors (southwesterly flow across the wind farm). The observations and simulations are for July 5, 2007 at 24:00 Pacific Standard Time (PST) (stable condition), 20:00 PST (near-neutral condition), and 12:00 PST (convective condition).

\section{Acknowledgements}

The authors express appreciation to Iberdrola Renewables, Inc. for sharing their wind farm data. This work was funded by the Department of Energy's Wind and Water Power Program Office under the Renewable Systems Interconnect Support Program (BNR-EB2502010) and performed under the auspices of the US Department of Energy by Lawrence Livermore National Laboratory under Contract DE-AC5207NA27344. LLNL is operated by Lawrence Livermore National Security, LLC, for the DOE, National Nuclear Security Administration under Contract DE-AC52-07NA27344. NREL is a national laboratory of the US Department of Energy, Office of Energy Efficiency and Renewable Energy, operated by the Alliance for Sustainable Energy, LLC.

\section{References}

Adams, M.S., Keith, D.W., 2007. A wind farm parameterization for WRF. In: $8^{\text {th }}$ Annual WRF Users' Workshop, June 11-15, 2007, Boulder, CO, Abstract 5.5, 4 pp.

Ainslie, J.F., 1988. Calculating the field in the wake of wind turbines. J. Wind Engin. Ind. Aerodyn. 27: 213-224.

Barthelmie, R.J., Frandsen, S.T., Hansen, K., Schepers, J.G., Rados, K., Schlez, W., Neubert, A., Jensen, L.E., Neckelmann, S., 2009. Modelling the impact of wakes on power output at Nysted and Horns Rev. In: European Wind Energy Conference, 2009. 
Barthelmie, R.J., Jensen, L.E., 2010. Evaluation of wind farm efficiency and wind turbine wakes at the Nysted offshore wind farm. Wind Energy 13: 573-586.

Chamorro, L.P., Porte-Agel, F., 2009. A wind-tunnel investigation of wind-turbine wakes: boundary-layer turbulence effects. Boundary-LayerMeteorol. 132: 129-149.

Conzemius RJ., 2010. Wind turbine and sodar observations of wakes in a large wind farm. $19^{\text {th }}$ Symposium on Boundary Layers and Turbulence, Keystone, Colorado, USA, American Meteorological Society, abstract P2B.4, 7 pp.

Dahlberg, J.A., Poppen, M., Thor, S.E., 1991. Load/fatigue life effects on a wind turbine generator in a wind farm. In: European Wind Energy Conference, 1991.

Elliott, D.L, Cadogan, J.B., 1990. Effects of wind shear and turbulence on wind turbine power curves. Proc. European Community Wind Energy Conference and Exhibition, Madrid, Spain.

Elliott, D.L., 1991. Status of wake and array loss research. In: WindPower Conference, Palm Springs, CA, USA.

Fitch, A., Olson, J., Lundquist, J.K., Dughia, J., Gupta, A., Michelakes, J., Barstad, I., 2011.

Parameterizations of wind farms in a mesoscale NWP model. In: 12 ${ }^{\text {th }}$ Annual WRF User's Workshop, Boulder, Colorado, June 20-24, 2011, P16.

Hand, M.M., Kelley, N.D., Balas, M.J., 2003. Identification of wind turbine response to turbulent inflow structures. NREL/CP-500-33465.

Hansen, K.S., Barthelmie, R.J., Jensen, L.E., Sommer, A., 2012. The impact of turbulence intensity and atmospheric stability on power deficits due to wind turbine wakes at Horns Rev wind farm. Wind Energy 15: 183-196.

Jimenez, A., Migoya, E., Esteban, M., Gimenez, D., Garcia, J., Crespo, A., 2011. Influence of topography and wakes on wind turbulence: measurements and interpretation of results. Wind Energy 14: 895-908.

Käsler, Y., Rahm, S., Simmet, R., Trujillo, J.-J., 2009. Wake measurements of a multi-MW wind turbine with long lidar. Conference Proceedings: Euromech Colloquium 508, 20-22 October 2009, Madrid, Spain, 3 pp.

Kelley, N.M., Osgood, R.M., Bialasiewisz, J.T., Jakubowski, A., 2001. Using wavelet analysis to assess turbulence/rotor interactions. Wind Energy 3: 121-134.

IEC (International Electromechanical Commission), 2003. Wind Turbine Generator Systems Part 12-1: Power Performance Measurements of Grid Connected Wind Turbines, Draft Technical Report No. IEC 61400-12-1.

Mann J., 2000. The spectral velocity tensor in moderately complex terrain. J. Wind Engin. Ind. Aerodyn. 88: 153-169.

Mann, J., Sorensen, J.N., Morthorst, P.-E., 2008. Wind energy, Environ. Res. Lett. 3, doi:10.1088/17489326/3/1/015001 
Marjanovic, N., 2011. Mesoscale and Large-Eddy Simulations for Wind Energy. LLNL-SR-471624, 20 pp., https://e-reports-ext.llnl.gov/pdf/471298.pdf

Marjanovic, N., Katopodes, F.C., Wharton, S., 2011. Comparisons of high-resolution simulations over increasingly complex terrain for wind energy applications. In: American Geophysical Fall Meeting, San Francisco, December 5-9, 2011, Abstract GC51J-04.

Neustadter, H.E., Spera, D.A., 1985. Method for evaluating wind turbine wake effects on wind farm performance. J. Solar Energy Engin. 107: 240-243.

Petersen E.L., Mortensen, N.G., Landberg, L., Højstrup, J., Frank, H.P., 1998. Wind power meteorology. Part 1: climate and turbulence. Wind Energy 1: 25-45.

Pichugina, Y.L., Banta, R.M., Brewer, W.A., Lundquist, J.K., Kelley, N.D., Hardesty, R.M., Alvarez, R.J., Mirocha, J.D., Sandberg, S.P., Weickmann, A.M., 2011. Wind turbine wake study by the NOAA High-Resolution Doppler Lidar. In: Coherent Laser Radar: Technology and Applications XVI Conference, June 2011, Long Beach, CA, USA, 4 pp.

Politis, E.S., Prospathopoulos, J., Cabezon, D., Hansen, K.S., Chaviaropoulos, P.K., Barthelmie, R.J., 2012. Modeling wake effects in large wind farms in complex terrain: the problem, the methods, and the issues. Wind Energy 15: 161-182.

Porte-Agel, F., Wu, Y.-T., Lu, H., Conzemius, R.J., 2011. Large-eddy simulation of atmospheric boundary layer flow through wind turbines and wind farms. J. Wind Eng. Ind. Aerodyn. 99: 154-168.

Rooijmans, P., 2004. Impact of Large-Scale Offshore Wind Farm Meteorology: Numerical Simulations with a Mesoscale Circulation Model. Masters thesis, Utrecht University, Utrecht, The Netherlands.

Roy, S.B., Pacala, S., Walko, R., 2004. Can large wind farms affect local meteorology? J. Geophys. Res. 109: D19101.

Sanderse B., 2009. Aerodynamics of Wind Turbine Wakes: Literature Review. Energy Research Centre of the Netherlands, Report \#ECN-E--09-016, April 2009, 46 p.

Schepers, J.G., 2003. ENDOW: Validation and improvement of ECN's wake model. ECN-C-03-034, Energy Research Centre of the Netherlands, ECN, March 2003.

Schepers, J.G., Obdam, T.S., Prospathopoulos, J., 2012. Analysis of wake measurements from the ECN Wind Turbine Test Site Wieringermeer, EWTW. Wind Energy, in press, DOI: 10.1002/we.488

Silva Lopes, A., Palma, J.M.L.M., Castro, F.A., 2007. Simulation of the Askervein flow. Part 2: largeeddy simulations. Boundary-Layer Meteor. 125: 85-108.

Tindal, A.J., 1993. Dynamic loads in wind farms I. GH report 205/R/12, Garrad Hassan \& Partners, May 1993.

Verheij, F.J., Cleijne, J.W., Voutsinas, S.G., Huberson, S., Crespo, A., Delaunay, D., Taylor, G., 1993. Wake and wind farm modeling, In: European Community Wind Energy Conference, Travemunde, Germany, 400-403 pp. 
Vermeer. L.J., Sørensen, J.N., Crespo, A., 2003. Wind turbine wake aerodynamics. Progr. Aerospace Sci. 39: 467-510.

Wharton, S., Lundquist, J.K., 2010. Atmospheric Stability Impacts on Power Curves of Tall Wind Turbines - an Analysis of a West Coast North American Wind Farm, LLNL-TR-424425, February 23, 2010, $75 \mathrm{pp}$.

Wharton, S., Lundquist, J.K., Marjanovic, N., Williams, J.L., Rhodes, M., Chow, T.K., Maxwell, R., 2011. Review of Wind Energy Forecasting Methods for Modeling Ramping Events, LLNL-TR-476934, March 29, 2011, 76 pp.

Wharton, S., Lundquist, J.K., 2012a. Assessing atmospheric stability and its impacts on rotor-disk wind characteristics at an onshore wind farm. Wind Energy, in press, doi:10.1002/we.483

Wharton, S., Lundquist, J.K., 2012b. Atmospheric stability affects wind turbine power collection. Environ. Res. Letters 7: doi:10.1088/1748-9326/7/1/014005

Wußow, S., Sitzki, L., Hahm, T., 2007. 3D-Simulation of the turbulent wake behind a wind turbine, Journal of Physics: Conference Series 75 (2007) 012033 [The Science of Making Torque from Wind], doi:10.1088/1742-6596/75/1/012033।

Zahle, F., Sørensen, N.N., 2008. Overset Grid Flow Simulation on a Modern Wind Turbine. AIAA Paper 2008-6727. 